\title{
The Detection and Analysis of Chitinase Activity from the Yeast Form of Candida albicans
}

\author{
By KEITH BARRETT-BEE* AND MARK HAMILTON \\ Imperial Chemical Industries PLC, Pharmaceuticals Division, Mereside, Alderley Park, \\ Macclesfield, Cheshire SK10 4TG, UK
}

(Received 5 January 1984; revised 23 March 1984)

\begin{abstract}
Chitinase activity was detected in the supernatant fraction of a high-speed centrifugation preparation of broken Candida albicans yeast cells. The enzyme showed peak activity during the rapid budding phase of growth and was found to parallel the chitin synthase activity. The optimum conditions for the hydrolysis of chitin, regenerated from acetylation of chitosan, were determined. Analysis of the kinetics of the enzyme-substrate interaction and a measurement of their binding suggests that an equilibrium binding situation exists and that the kinetics follow a Langmuir isotherm interaction.
\end{abstract}

\section{INTRODUCTION}

Enzymes which degrade chitin are widely distributed in nature and have been detected in many micro-organisms and in the digestive tracts of many animals which feed on chitincontaining organisms (Mommsen, 1978). The enzymic hydrolysis of chitin to $N$-acetyl-Dglucosamine is performed by two enzymes working consecutively. These are poly[1,4- $\beta-(2-$ acetamido-2-deoxy-D-glycoside) glycanohydrolase] (EC 3.2.1.14), chitinase, which removes chitobiose units, and chitobiose acetaminodeoxyglycohydrolase (EC 3.2.1.30), chitobiase, which degrades this disaccharide to its monomer subunits.

Chitin in fungi comprises an important structural part of the cell wall, especially in the filamentous fungi and the Basidiomycetes where it comprises up to $16 \%$ of the dry weight of the organism (Gooday, 1979). In yeasts the amount of chitin in the cell wall is much lower but it is nevertheless important, particularly in the budding process. Bud scars have been shown to be largely composed of chitin (Cabib \& Bowers, 1971). Chitin, which gives structural strength to the organism, is formed by polymerization of $N$-acetyl-D-glucosamine from the activated precursor uridine diphosphate $N$-acetyl-D-glucosamine by the enzyme chitin synthase. Since chitin is important in the growth of fungi it is most likely that there exists a system whereby it can be remodelled by a concerted breakdown and build-up to allow a degree of plasticity in the wall, which would be important in budding and in the elongation of hyphae. Indeed it has been shown that Polyoxin D, which inhibits chitin synthase, causes cell lysis (Gooday, 1977). The enzyme which breaks down chitin prior to remodelling is then likely to be an important enzyme in development; indeed Gooday has shown high chitinase activity in the hyphal tips of Mucor (Gooday \& Trinci, 1980). In this paper we describe the chitinase of the dimorphic fungus Candida albicans and quantify its presence during a growth cycle.

\section{METHODS}

Media and growth conditions. Cultures of $C$. albicans NCPF 3153 were maintained on Sabouraud's dextrose slopes (Mycological Peptone, Oxoid, $10 \mathrm{~g}^{-1}$ ) and stored at room temperature. Liquid cultures were grown in 1litre batches in Sabouraud's dextrose in a rotary incubator at $37{ }^{\circ} \mathrm{C}$ and 200 r.p.m. following inoculation with stationary phase cells at a density of $10^{6}$ cells $\mathrm{ml}^{-1}$. Under these conditions the organisms grew exclusively in the yeast phase. 
Cell breakage and fractionation. Organisms were harvested by centrifugation at $4{ }^{\circ} \mathrm{C}$, washed twice with distilled water and re-suspended in Tris/ $\mathrm{HCl}\left(0.05 \mathrm{~mol} \mathrm{l}^{-1} \mathrm{pH} 7\right)$. The organisms were broken in a Braun disintegrator using $0.4 \mathrm{~mm}$ beads. The broken cell preparation was centrifuged at $5000 \mathrm{~g}$ for $15 \mathrm{~min}$ to remove unbroken yeasts and then at $100000 \mathrm{~g}$ for $1 \mathrm{~h}$ and the resultant pellet and supernatant fractions retained for enzymic determinations.

Chitinase assay. Chitinase activity was measured by a modification of the method of Molano et al. (1977) using $\left[{ }^{3} \mathrm{H}\right.$ ]acetic anhydride $\left(500 \mathrm{mCi} \mathrm{mmol}^{-1} ; 18.5 \mathrm{GBq} \mathrm{mmol}^{-1}\right)$ to acetylate the chitosan. Crab cell chitosan was obtained from Sigma. The final chitin preparation was ball-milled with Pyrex beads for $72 \mathrm{~h}$ to produce a very fine suspension. The preparation was stored at $20 \mathrm{mg} \mathrm{ml}^{-1}$. Chitinase activity was measured by incubating $0.05 \mathrm{ml}$ enzyme preparation $\left(100 \mu \mathrm{g}\right.$ protein) together with $0.1 \mathrm{ml}$ chitin suspension in phosphate buffer $\left(0 \cdot 1 \mathrm{~mol} 1^{-1}\right)$ typically at $\mathrm{pH} 6.5$ in plastic tubes. The reaction was stopped by boiling for $20 \mathrm{~min}$. Particulate chitin was separated from digested products by filtration through a Whatman GF/F filter and the filtrate counted by liquid scintillation counting in PCS liquid scintillant (Amersham). The filtration method was found to be more reproducible than centrifugation due to the fineness of the precipitate, which allowed some trailing on the meniscus. Results are expressed as pmol $N$-acetylglucosamine released (mg dry wt) $)^{-1} \mathrm{~min}^{-1}$ based on the known specific activity of the acetic anhydride. Chitinase activity was detected in the supernatant fluid and high-speed pellet. All work described below refers to the supernatant enzyme.

Chitin synthase assay. Total chitin synthase activity was measured in the pellet fraction according to the method of Adams \& Gooday (1980) following activation with trypsin. All experiments were performed in quadruplicate and repeated several times.

Equilibrium binding experiments. The adsorption-desorption experiment was carried out by adding chitinasecontaining buffer to a suspension of non-isotopically labelled chitin $\left(1 \mathrm{mg} \mathrm{ml}{ }^{-1}\right)$ and incubating for $5 \mathrm{~min}$ at $25^{\circ} \mathrm{C}$; the chitin was sedimented by centrifuging in a bench centrifuge. The supernatant was removed and the chitin resuspended in an equal volume of buffer. After a further $5 \mathrm{~min}$ the chitin was again removed by centrifugation and the two supernatants analysed for chitinase activity as before. The unlabelled chitin was prepared in the same way as radiolabelled chitin except that unlabelled acetic anhydride was used.

Determination of molecular weight. Separation and molecular weight determinations were performed using molecular exclusion chromatography with Sephadex G-200. A $1000 \times 150 \mathrm{~mm}$ column was used with a flow rate of $10 \mathrm{ml} \mathrm{h}^{-1}$ using Tris/HCl $\mathrm{pH} 7\left(50 \mathrm{mmol}^{-1}\right)$. A standard curve was constructed using bovine $\gamma$-globulin, bovine serum albumin, ovalbumin and $\delta$-chymotrypsin. Column eluent was monitored for chitinase activity as before. Protein concentration was measured using the method of Lowry with 'Lab Trol' (Merz \& Dade AG, Dudingen, FRG) as standard.

\section{RESULTS AND DISCUSSION}

Chitinase and chitin synthase were measured in the high-speed supernatant and pellet fractions respectively as a function of the age of culture of $C$. albicans (Fig. 1). The activity of both enzymes, when expressed as activity per mg dry weight of cells in the culture or as total activity in the culture, showed a peak in the early exponential phase of growth. Microscopic examination of cultures taken at this time indicated that most cells were budding and presumably had a need for chitin remodelling. These results suggest that chitinase is important in fungal growth and may be a potential target for antifungal chemotherapy; thus inhibition might render the cell non-plastic, whilst stimulation may induce autolysis. In view of the above findings subsequent studies were carried out with organisms harvested $8 \mathrm{~h}$ after inoculation into fresh medium.

\section{Optimum conditions for chitinase assay}

When the temperature of incubation was varied it was found that chitinase activity was stable and had a temperature optimum of $50^{\circ} \mathrm{C}$; this type of result is common amongst small hydrolytic enzymes. All subsequent experiments were carried out at $37^{\circ} \mathrm{C}$, since this is the temperature at which the pathogen would find itself in the human host. As the enzyme showed a broad $\mathrm{pH}$ dependence with an optimum around $6 \cdot 5$, subsequent assays were performed at this $\mathrm{pH}$ using phosphate buffer. Little dependence on ionic strength was observed.

Chitinase activity against time, and activity against enzyme concentration experiments were performed for each enzyme and substrate preparation to ensure optimum working conditions. Standard conditions were chosen where activity was on the linear portion of a progress and concentration curve. 


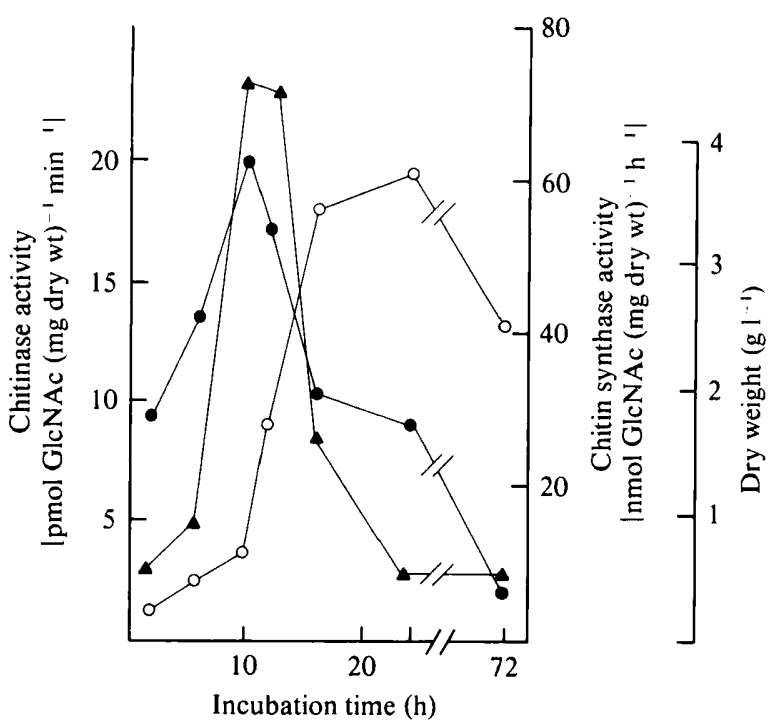

Fig. 1. Variation of activity of chitin synthase and chitinase with the age of a culture of Candida albicans. Enzyme activities were measured in the $100000 \mathrm{~g}$ pellet (chitin synthase, $\Delta$ ) and $100000 \mathrm{~g}$ supernatant (chitinase, $O$ ). $\bigcirc$, Growth curve expressed as dry weight.

At high substrate concentrations high blank values were observed, which could be attributed to either small radiolabelled chitin fragments or soluble chitodextrins passing through the filter and appearing in the filtrate. If adequate controls were not used it was possible to get curved Lineweaver-Burk plots.

Molecular exclusion chromatography using Sephadex G-200 and several known molecular weight standards showed an approximate molecular weight of 70000 (see Methods). This is a larger molecular weight than found for some chitinases (Mommsen, 1980).

\section{Enzyme kinetics}

Since chitin is an insoluble substrate, appearing under the light microscope as a clump of fibrils, the significance of conventional solution kinetics is not clear. In an experiment where the substrate concentration was varied at different enzyme concentrations and the hydrolysis of chitin measured and plotted in a reciprocal manner, a common intercept on the $x$ axis was obtained, indicating a constant $K_{\mathrm{m}}$. However, each chitin preparation gave a different apparent $K_{\mathrm{m}}$ with a single enzyme preparation; these results probably reflect the state of subdivision of the particles, since with finer particles there was apparently more enzyme activity.

As enzyme activity under given conditions depends on substrate concentration, then clearly the enzyme must be able to interact with more than one chitin particle. The mode of hydrolysis of the polymer could either be one of sequential 'nibbling' along a chain, removing chitobiose units as it goes, or one of removing a disaccharide unit, then detaching and rejoining the same or another particle. In either case, for there to be a dependence on substrate concentration there must be some form of adsorption-desorption and a 'seeking' of chitin particles. To investigate the question of 'nibble' against 'chop', enzyme was allowed to adsorb either radiolabelled or nonradiolabelled chitin particles for $5 \mathrm{~min}$. An equal amount of chitin was then added, either radiolabelled or not, therefore altering the specific activity of the pool. The incubation was continued, and terminated after $10 \mathrm{~min}$. The results of the experiment (Table 1) show that there was identical release of radioactivity in mixed incubations, irrrespective of whether the initial chitin was radiolabelled or not. If a 'nibble' mechanism was important then the primary addition of chitin would predominate (non-radiolabelled products would not be detected), but there was no evidence for this. Thus there appears to be an equilibrium between radiolabelled and non-radio- 


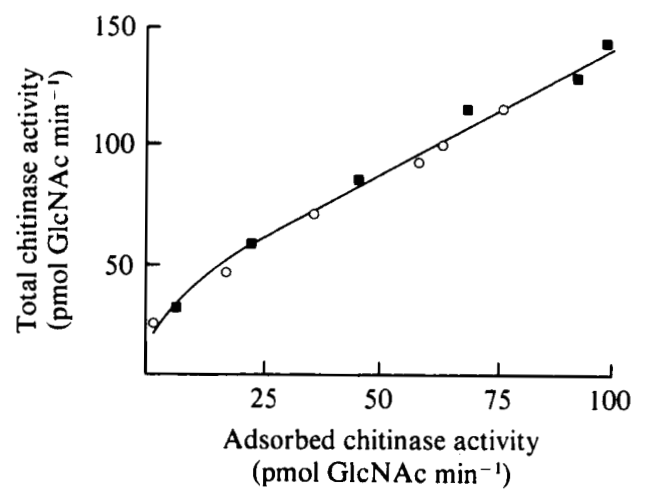

Fig. 2. Adsorption-desorption curve for chitinase and chitin. $\square$, Primary adsorption after $5 \mathrm{~min}$; $\bigcirc$, adsorbed activity after the removal of supernatant and replacing it with fresh buffer. The experiment was carried out at $25^{\circ} \mathrm{C}$; enzyme assays were as described in the text.

Table 1. Effect on enzyme activity of two consecutive additions of chitin to chitinase

\begin{tabular}{|c|c|}
\hline \multicolumn{2}{|c|}{ Chitin type } \\
\hline 1st addition & 2nd additic \\
\hline${ }^{3} \mathrm{H}$ & ${ }^{1} \mathbf{H}$ \\
\hline${ }^{1} \mathrm{H}$ & ${ }^{3} \mathbf{H}$ \\
\hline${ }^{3} \mathrm{H}$ & ${ }^{3} \mathrm{H}$ \\
\hline${ }^{3} \mathrm{H},{ }^{1} \mathrm{H}$ & - \\
\hline
\end{tabular}

$$
\begin{aligned}
& \text { Apparent activity* } \\
& \text { [pmol min }{ }^{-1} \pm \text { SD } \\
& \text { (4 determinations)] } \\
& 36.9 \pm 3.7 \\
& 36.2 \pm 1.7 \\
& 75.8 \pm 5.1 \\
& 35.9 \pm 2.7
\end{aligned}
$$

- Apparent activity is measured by release of radioactive fragments following the two additions; non-radioactive chitin does not give any activity, it merely reduces the specific activity of the pool. The concentrations of the two chitin preparations were adjusted to make them equally active substrates.

labelled substrate in a double incubation. This means that during hydrolysis of chitin particles the chitinase binds to and is then released from the particle surface with the removal of a chitobiose unit.

The results of the kinetic studies indicate Michaelis-Menten type kinetics suggesting that the chitinase may be relatively simple, similar to those of Streptomyces species and Coprinus cinereus (K. Barrett-Bee, unpublished observations), and unlike that of the tobacco hook worm, which has been shown to be cooperative with regard to its substrate (Bade \& Stinson, 1979). The observations showing linear kinetics suggest that control of $C$. albicans chitinase activity in the cell may be by means of enzyme concentration rather than by allosteric actions; attempts to detect any activating or inhibiting factors present in yeast have not been successful. Skujins $e t$ al. (1973) have examined the adsorption of Streptomyces chitinase and lysozyme to chitin and demonstrated that at $0{ }^{\circ} \mathrm{C}$ there was a degree of hysteresis between adsorption and desorption as judged by optical density measurements, suggesting that there is no equilibrium. They concluded that kinetic derivations based on a Langmuir isotherm model were not tenable. However, the results obtained with $C$. albicans chitinase (Fig. 2) argue to the contrary and indicate that this enzyme does follow equilibrium binding kinetics. When the binding of chitinase to chitin was measured together with its desorption as described above, there was clearly no hysteresis between the two sets of data, i.e. adsorption and desorption, indicating that an equilibrium existed between bound and free enzyme. The binding curve did, however, show departure from linearity at low chitinase activities. The reason for this is not clear, but it implies cooperative binding, possibly as a result of limited digestion 'opening up' enzyme sites. A similar very early 'processing' phenomenon has been found with bacterial chitinase. At early times of incubation of enzyme with chitin particles there is a marked lag period in the rate curve $(R . A$. Smucker, personal communication). 


\section{REFERENCES}

ADAMS, D. J. \& GoODAY, G. W. (1980). A rapid chitin synthase preparation for the assay of potential fungicides and insecticides. Biotechnology Letters 2, 75-78.

Bade, M. L. \& Stinson, A. (1979). Molting fluid chitinase a homotropic allosteric enzyme. Biochemical and Biophysical Research Communications 87, 349-353.

CABIB, E. \& Bowers, B. (1971). Chitin and yeast budding, localisation of chitin in yeast bud scars. Journal of Biological Chemistry 246, 152-159.

GOODAY, G. W. (1977). Biosynthesis of the fungal wall, mechanisms and implications. Journal of General Microbiology 99, 1-11.

GOODAY, G. W. (1979). Biosynthesis of the fungal wall, mechanisms and implications. In Fungal Wall and Hyphal Growth (British Mycological Society Symposia, vol. 2), pp. 203-223. Edited by J. Burnett \& A. Trinci. Cambridge: Cambridge University Press.
GoOdAY, G. W. \& TrINCI, A. (1980). Wall structure and biosynthesis in fungi. Symposia of the Society for General Microbiology 30, 207-251.

Molano, J., Duran, A. \& Cabib, E. (1977). A rapid and sensitive assay for chitinase using tritiated chitin. Analytical Biochemistry 83, 648-656.

Mommsen, T. P. (1978). Digestive enzymes of a spider, Tegenaria atricia Koch. Comparative Biochemistry and Physiology 60A, 371-375.

Mommsen, T. P. (1980). Chitinase and $\beta$ - $N$-acetylglucosaminidase from the digestive juice of the spider Cupiennis salei. Biochemica et biophysica acta 612, 361-372.

Skujins, J., Pukite, A. \& Mclaren, A. D. (1973). Adsorption and reactions of chitinase and lysozyme on chitin. Molecular and Cellular Biochemistry 2, 221-228. 